\title{
Automation Technologies and Systems
}

\author{
Md Sadiqul Hasan Talukder \\ B.Sc. in Mechanical Engineer Department of Mechanical Engineering Rajshahi University of Engineering \& \\ Technology, Bangladesh
}

Abstract: This research work deals with the implication of modern retailing at Dhaka, Bangladesh with main objectives to find out technological activity, impact on modern welfare, future implementation.

Keywords: PLC, HMI, Technological activity, Human welfare, Operation, Efficiency.

\section{Introduction}

Two types of Device A) Human Machine Interface (HMI) \& B) Programmable Logic Controller (PLC) are described specially. This study is based on the data collection from an organized institution and manufacturers. This stored formats are considered for all Pharmaceutical Industries in Bangladesh.

A Region and year wise data is collected and complied using questionnaries. The data analysis covers the economical impact on Bangladesh. It would also be possible to find out the global economical impact and human welfare issue.

\section{Headings}

PLC and HMI in Coating machine controls all the production in Pharma machinery. In long years ago it had been done in manually but now this system is fully digitalized in modern era. There's some program are involving in PLC and HMI is needed to operate the production. It is outside of imagine that Pharmaceutical machinery profit from this function about 4.5 billions per year.

\section{Indentations}

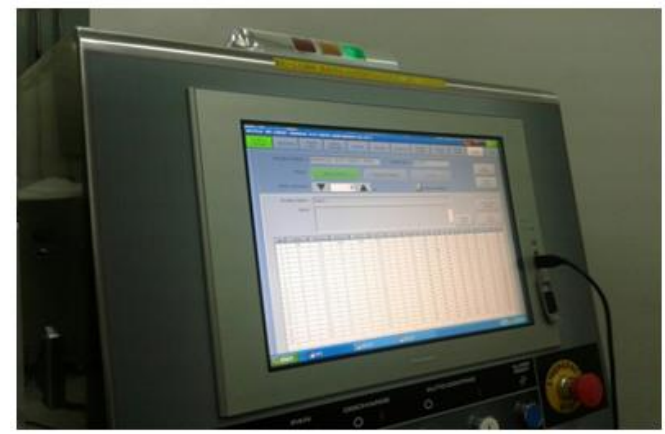

FIG: 1.1

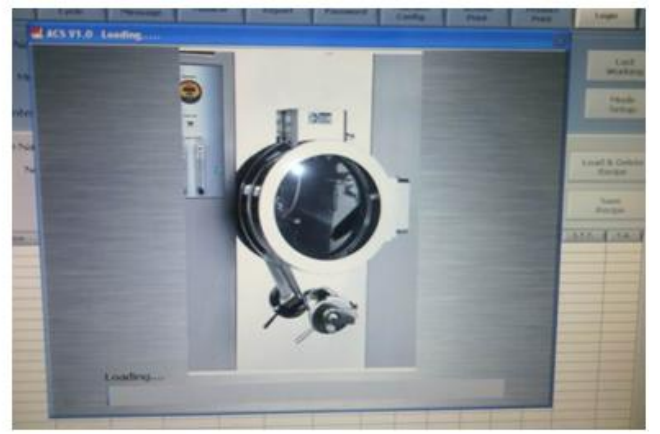

FIG: 1.2

It is HMI's first function(FIG:1.1 \& 1.2) where program from PLC automatically operate this section. This indicates that production is going to start by someone.

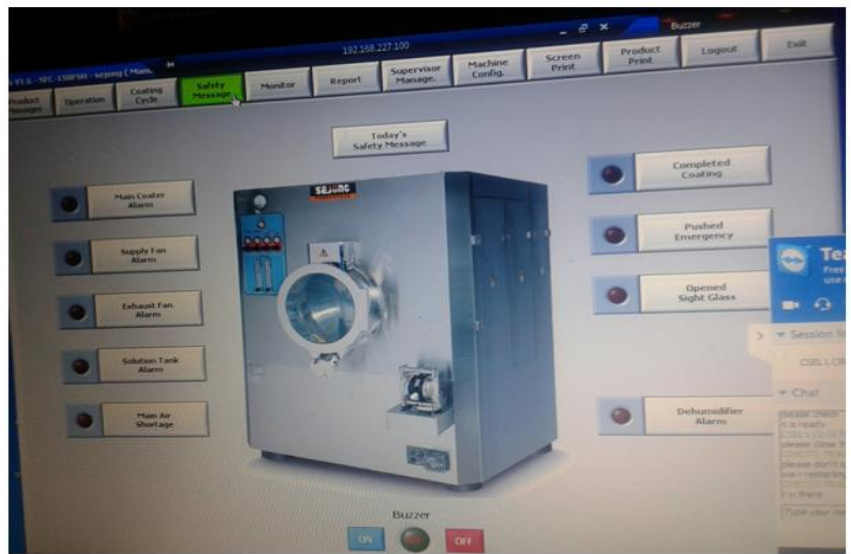

FIG:2 
Then how the product will be started selected from here (FIG:2). Here, the important part is main coater alarm and completed coating. This alarm defines that how the product will goes on frequently and how would it be stopped. Complete coating indicate that that production complete their cycles without any error. Some product are found in defective. But if product is finished then it complete the product without any error. Supply fan process the raw material to go on refining. Exhaust fan exits the impure air from the tanks. When raw material is entered then many impure substances are found. Then it needs to be exhausted. As product is prepared by raw materials and many types of solution. Therefore solution must be pure and it would be a qualified. Solution tank alarm indicate about the measurement of solution what products need to be. There are also others functions as Pushed emergency and Opened sight glass. These are the most valuable parts to finish the production completely.

As when the raw materials are going to be converted into product and then final product it would be then monitored (FIG:3). Two types of water are supplied into the processing zone. Dehumidifier and pressure must be setup at Standard temperature and Standard pressure. Duct washing and pan washing system is adjusted to the processing zone. It is miracle then when this all going then it could be controlled by an HMI monitoring system. Warm water is supplied because if the converting process does not go to the solid. If found in a solid position then it would be difficult to separate many solution able things. Though it would be given by a program that humidity and temperature must be in the room temperature but yet it sometimes it would be found that slightly changed of temperature and humidity it turns into a hard solid things. Detergents are used that raw materials are going into a clean position. If there is any air variation then air must be kept in a $0.00 \mathrm{Mpa}$. Here,

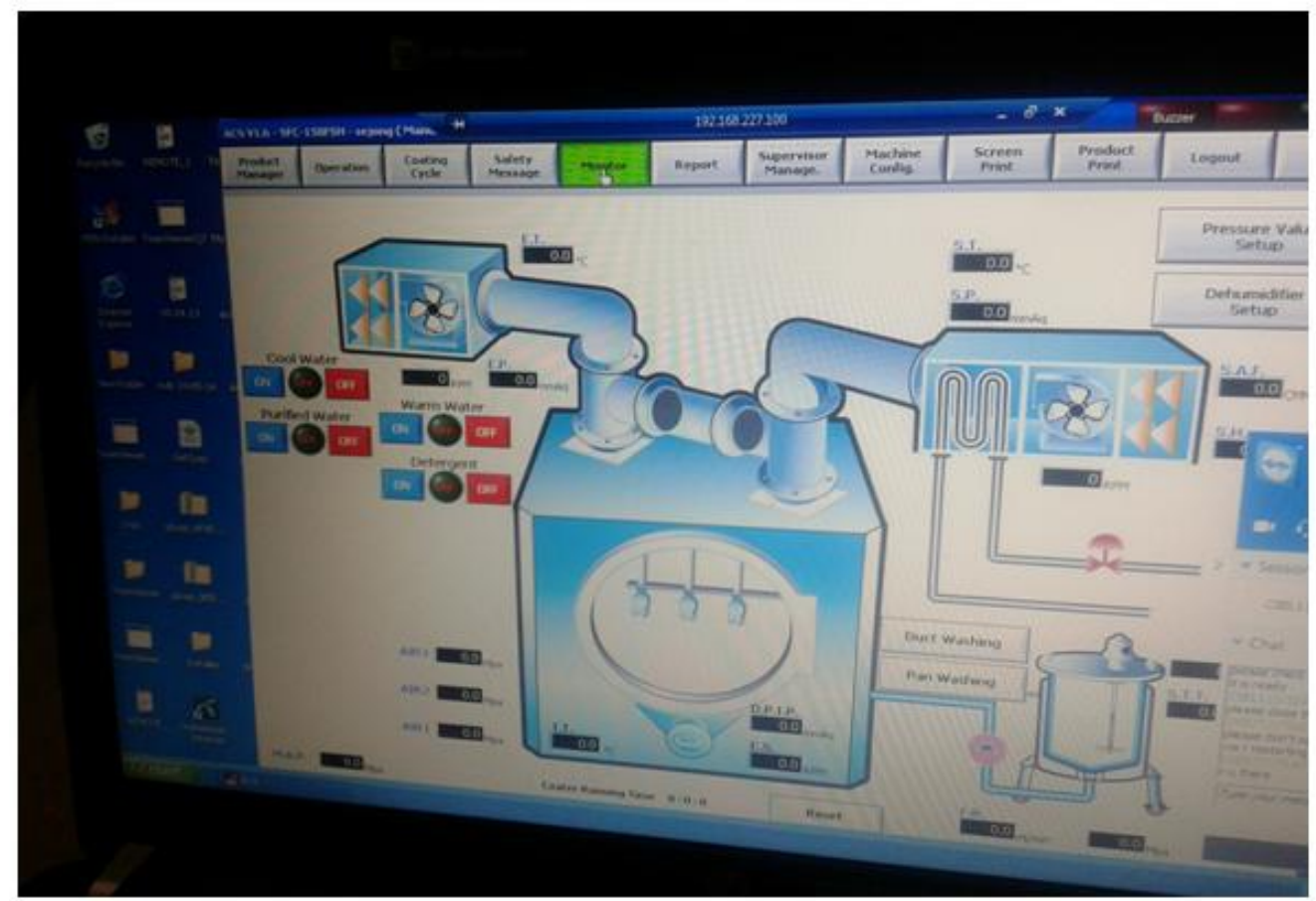

FIG:3

air is provided in to three different types. Therefore, it would be very needed that if any air variation must not be found. Pressure value and dehumidifier setup is necessary to manipulate the product completely.

If various type of product will be created in Pharmaceutical Industry then it can be also operated by the HMI (FIG: 4). Product manager option indicate what product will you produce in the near future. Batch products are also be made by this HMI operating system. As it is the pharmaceutical machine therefore film coating, sugar coating and C.I.P. is possible. But different type of production or in a huge volume in a large scale this option will be increased. Another type of machine then can be used to increase this option. However, when product is created then it must be verified and needs certification. This type of inspection is possible by HMI. As before production human use the operation system of HMI (FIG:4) and after done then they have to go to the coating system. It is needed because coating cycle is needed to fulfill the product requirement. Here another option added called Safety Message. It detect the product defection and find if any impurities are found in raw materials and solution then it can be rejected to operate by the HMI. Hence, Safety message also show the machine capability and machine life time cycle when the machine is operated. If there is any more criteria on the machine then it can be detected by safety message. The four systems e.g. product manager, operation, coating cycle, safety message this can be observed by monitor option. Monitor option is also created for 
monitoring another batch productions. As it is told before that processing of raw materials and soluble things before creating the final production can be shown or monitored this is the monitor option system. After monitoring then it should be needed that how much product is produced per day or per week or per month. Then report system can generate that how much product can produce it per day or per week or per month. If the products are faulty then it must be shown in the report. Hence, if machine cause an error then report could not show the perfect report of the production. It is found that sometimes operators cannot operate the machine properly then supervising is needed to observe the operation condition of the machine and inspection of the machine. Superviser also observe about the measurement of the production because sometimes operator select an error selection of that machine. As a result the quantity of the product cannot be found correctly. Then target is not fulfill that day or a month or a year. Supervisor also control the entire batch production operation, selection and product reliability. Machine configuration is needed for the various type of batch production.

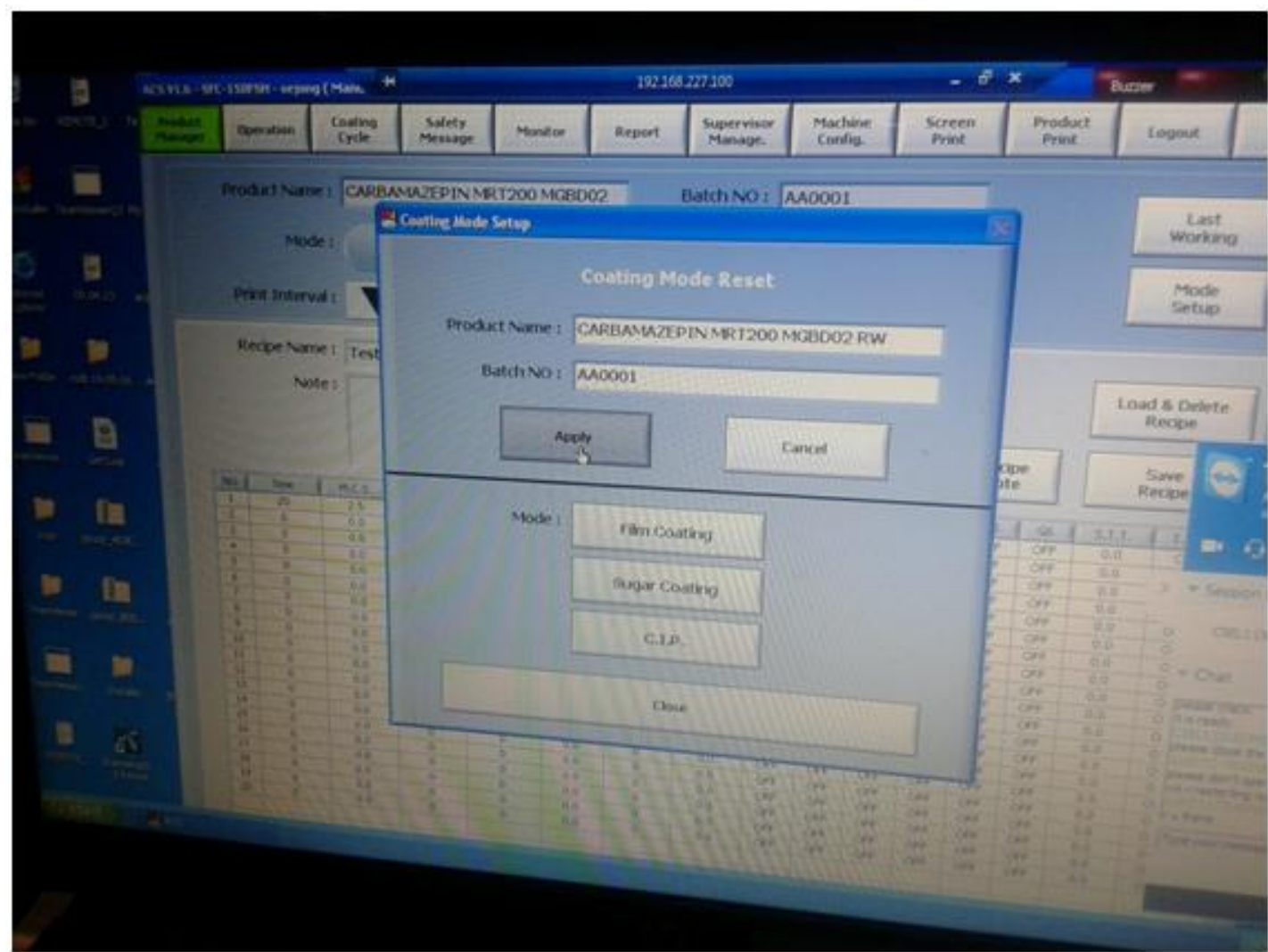

FIG: 4

Hence, there is no affect on the machine cycle if the machine is configured. As it is program based therefore, it is just configured to match with the various type of batch production. HMI also generate the total operation which created on HMI during the operation period of production. Screen print is responsible for this. When product is finalized then it need to be printed. Product print is responsible to print any product. After finishing all the operation Log out is needed to finish the operation of HMI. If logout is not properly then it affects on the machine operation system.

The HMI controlling the machine of Main coater, Exhaust fan, Supply fan and Tank Agitator (FIG: 5). At main coater, Coater speed is fixed into $3.00 \mathrm{rpm}$. Tablet temperature setup value is $45.0^{\circ} \mathrm{C}$ though it's present value is $27.0^{\circ} \mathrm{C}$. Limit of higher and lower should be 45.0 and 0.00 . When speed is exhausted then it is fixed into $2000.00 \mathrm{rpm}$. Exhaust temperature set up value is $40.0^{\circ} \mathrm{C}$ and present value is $28.2^{\circ} \mathrm{C}$. Limit of higher and lower should be 45.0 and 0.00. Main air pressure is needed to create a successful production. It is fixed in to $0.2 \mathrm{Mpa}$. Tank temperature setup value is $0.00^{\circ} \mathrm{C}$ and present value is also $0.00^{\circ} \mathrm{C}$. Higher limit and lower limit is both 0.00. It is remembered that Intermittent drive must be off that time. The interval should be 30 seconds. After interval then it will be running for 6 seconds. If two pumps are connected then each pump speed should be 5 $\mathrm{rpm}$. This time Heater is off. It is better if differential pressure is kept in a manual because pressure needs to be changed periodically. Hence this time the setup value must be 0.00 . Any type of batch production this type of operation must be needed. The finishing of products must be depended this type o operation. However, condition vary or if the situation vary but if the operation is done by this way then it is hardly said that 
successful production is found by this way. HMI system is a unique operation system where all types of batch production system is done. The main advantage is that it consumes times a lot. It is a fully digitalized program

where no more need of human hand. Human just operate it by the system. The more positive point is that it's monitoring system. For this supervisor easily controls all types of production. The modern era is fully depended on this system.

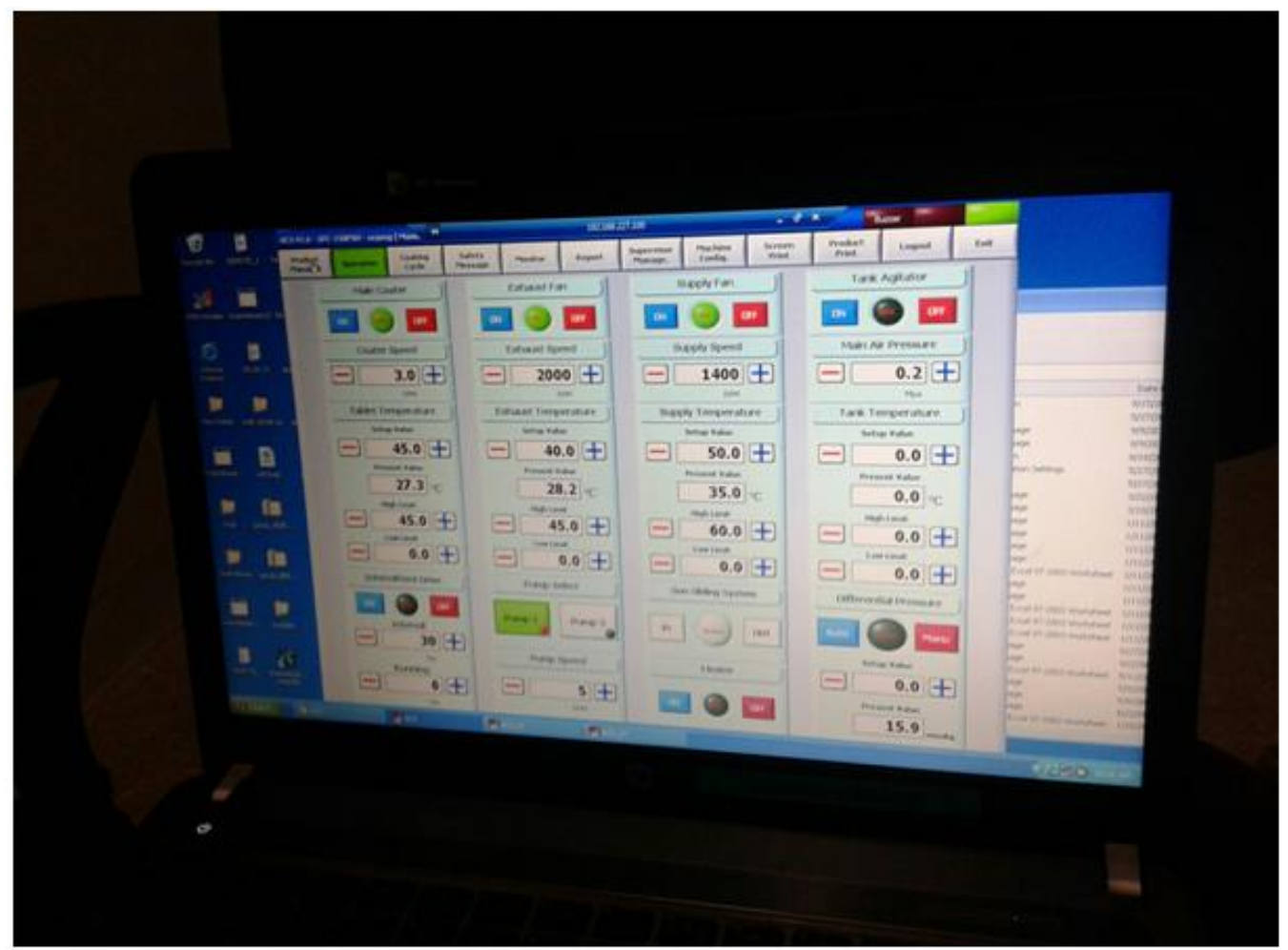

FIG: 5

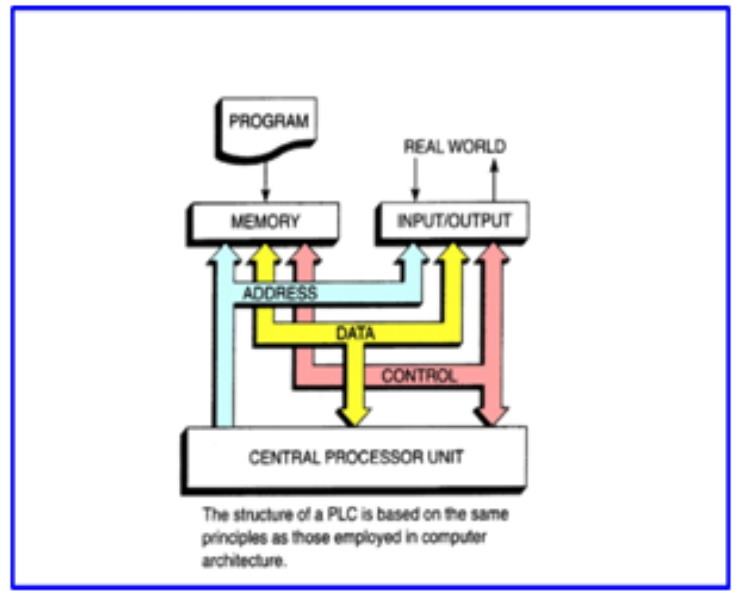

FIG: 6.1

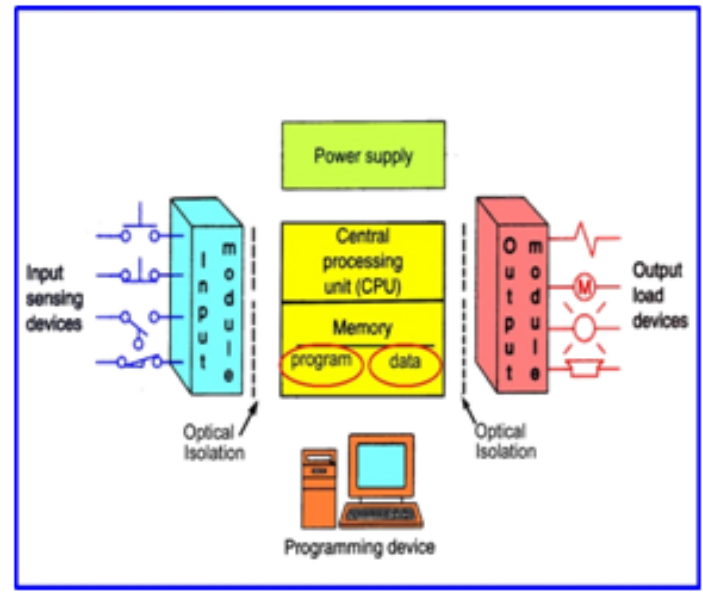

FIG:6.2

The Basic programming of PLC work is given below Here it is starting from central processing unit. (FiG:6.1). Then it sends the signal through the address which is connected to the input unit. Real world is attached herewith. Memory is used to store the program. Input sensing device is used to sense the product recommendation. (FIG:6.2). Out module is used to give the output of this program.Hence, it is cleared that it would be a fully computerized based. Memory contains two things: 1 . Program and 2. Data. 


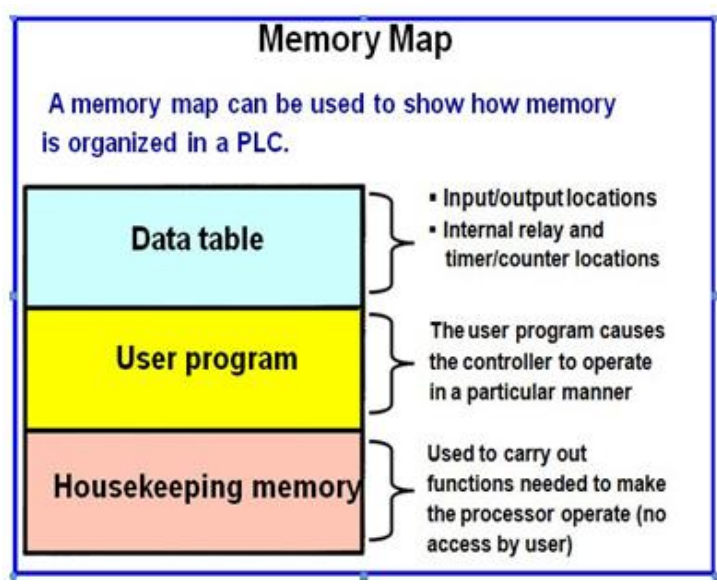

FIG:6.3

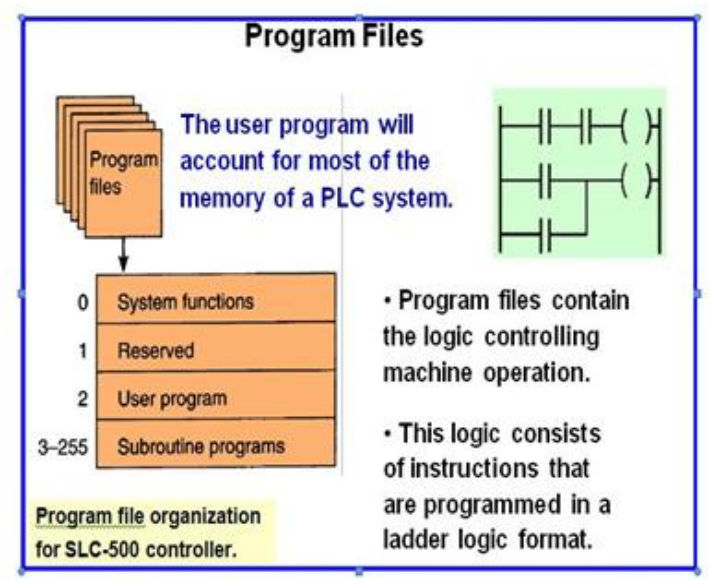

FIG:6.4

If memory is not organized then it is very difficult to generate any product description or product type. Therefore, a memory map is used to organize (FIG:6.3). Data table, User program, Housekeeping memory are the three main parts of memory map. Program file is needed is needed to locate the program. Otherwise, it can not be possible to generate any type of products at atime. Basicall, Progarm file contains four types(FIG: 6.4). 1. System functions, 2. Reserved, 3. User Programs, 4. Subroutine programs.

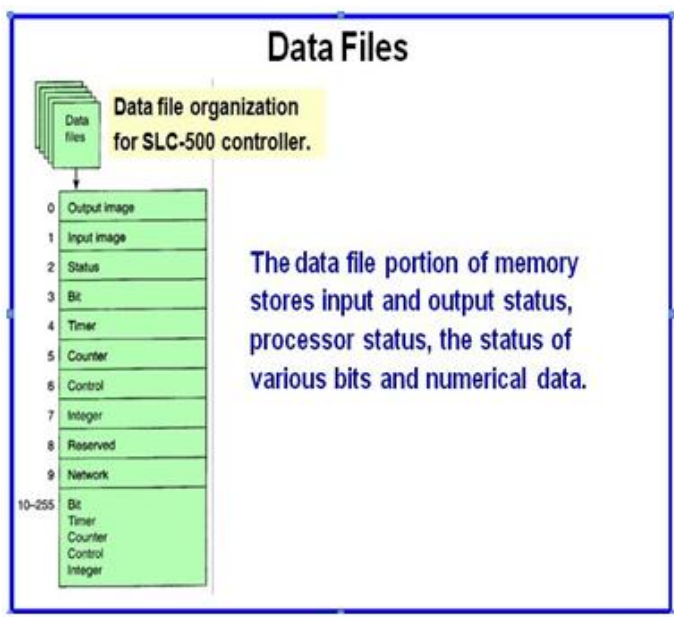

FIG: 6.5

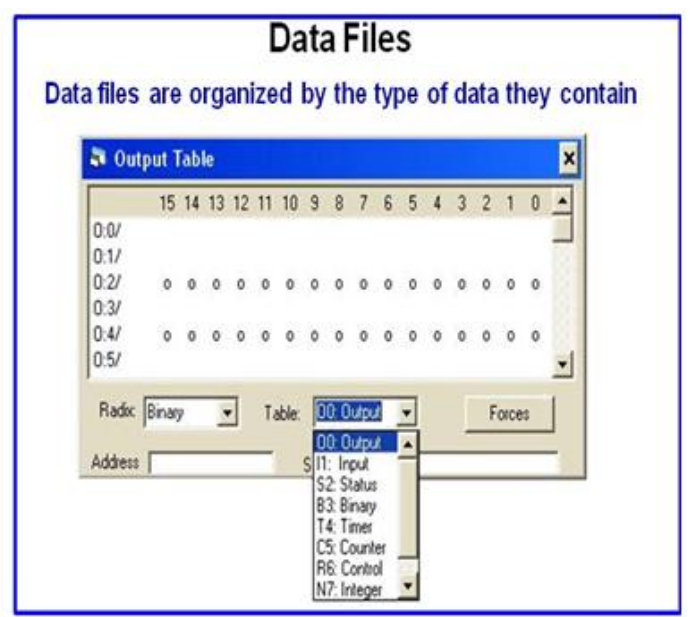

FIG: 6.6

Data files organization are used to keep many types of numerical data (FIG: 6.5). It contains output image, input image, status etc, bit, timer, counter, control, integer, reserved, network etc. Data files output table is also necessary to contain any data shown. Here, $0: 0 /, 0: 1 /$, the serial is 15 then its interval 0 . Same type $0: 1 /$, $0: 2$, the serial is 15 then interval is 0 . Actually it is a binary type. Therefore, 0 or 1 will be shown. When input module switch is opened then Binary 0 is stored. Here, data table files keep the input image. In case of output file operation stored binary 0 is activated from from the data table files output image. Here, processor continually deactivates output status. Then out put side is on and going to the program scan. I/O scan records status data of input devices. It energizes output devices that have their associated status bits set to on. Program scan instructions are executed sequentially. Because, the input can change at any time, the PLC must carry on this process continuously. The scan frame indicates how fast the controller can react to change in inputs. Scan times vary with computer model and program content and length. If a controller has to react to an input signal that changes states twice during the scan time, it is possible that the PLC will never be able to detect this change. Scan time may be a concern in high speed operations. 


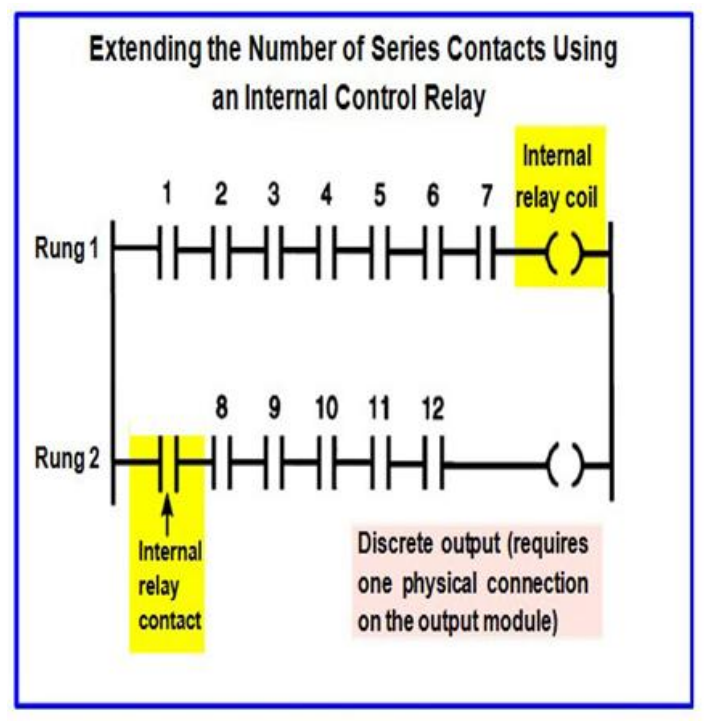

FIG: 6.7

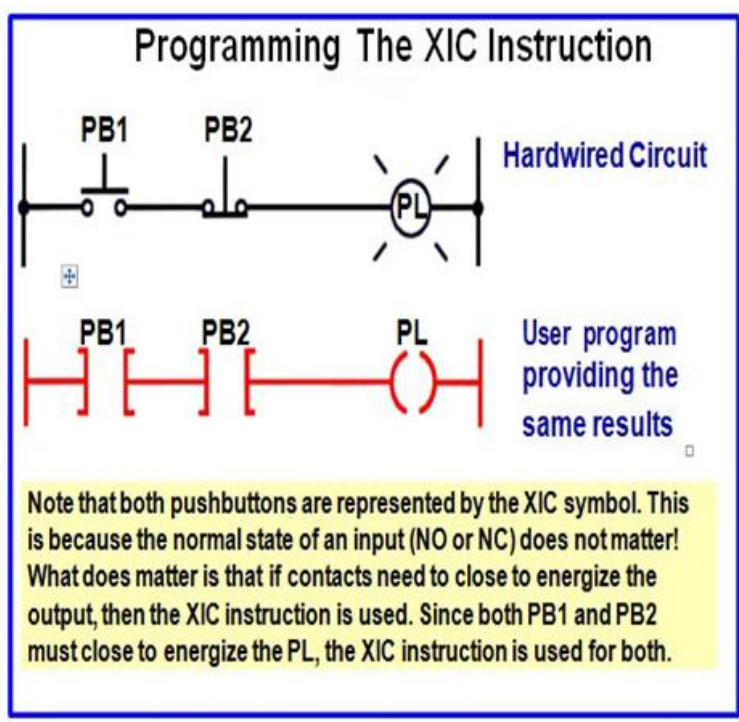

FIG:6.8

Incase of extending the number of series contacts relay is used(FIG: 6.7). Internal relay coil also added to it. It's first rung has 7 parts and second rung has 5 parts. Discrete putput also be required. After that, programming is donr by the XIC instruction (FIG: 6.8). Hardware circuit is one of the part of the programming unit. Here, push button is also needed.

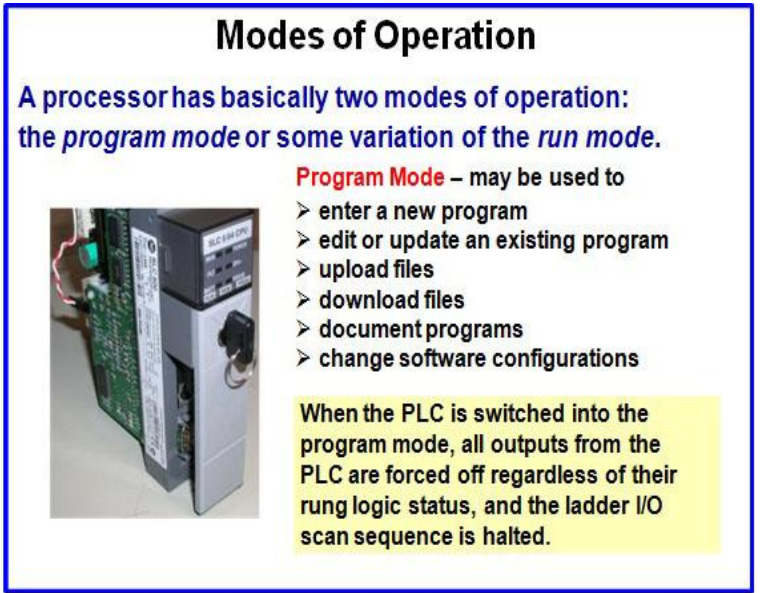

FIG: 6.9

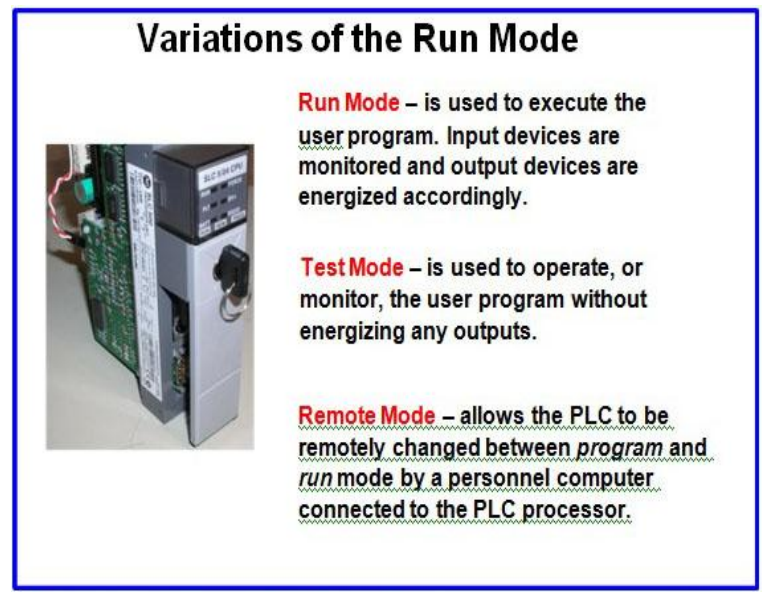

FIG: 6.10

Heres, the mode of operation and variation of run mood is needed (FIG: 6.9 and 6.10). In case of mode of operation a processor is used. It has a program mode which is responsible to operate the PLC. It depends on the entering of a new program. By the changing of software configurations PLC program would be changed. Run mode is used to execute the program. Test mode is used to operate the program. Then remote mode is needed to complete the finalization of the program. Moreover, this is the additional part of this program. But in a modern era these are very veryimportant to implement a successful running of PLC. However, select processor type screen, I/O screen, Data file screen are the vulnerable parts of the PLC. Monitoring a Ladder Logic program is another successful operation of PLC in a modern era. Highlighted rungs indicate that the instruction is true. 
As visting on Novartis (Bangladesh) Limited the graph is shown as belows:

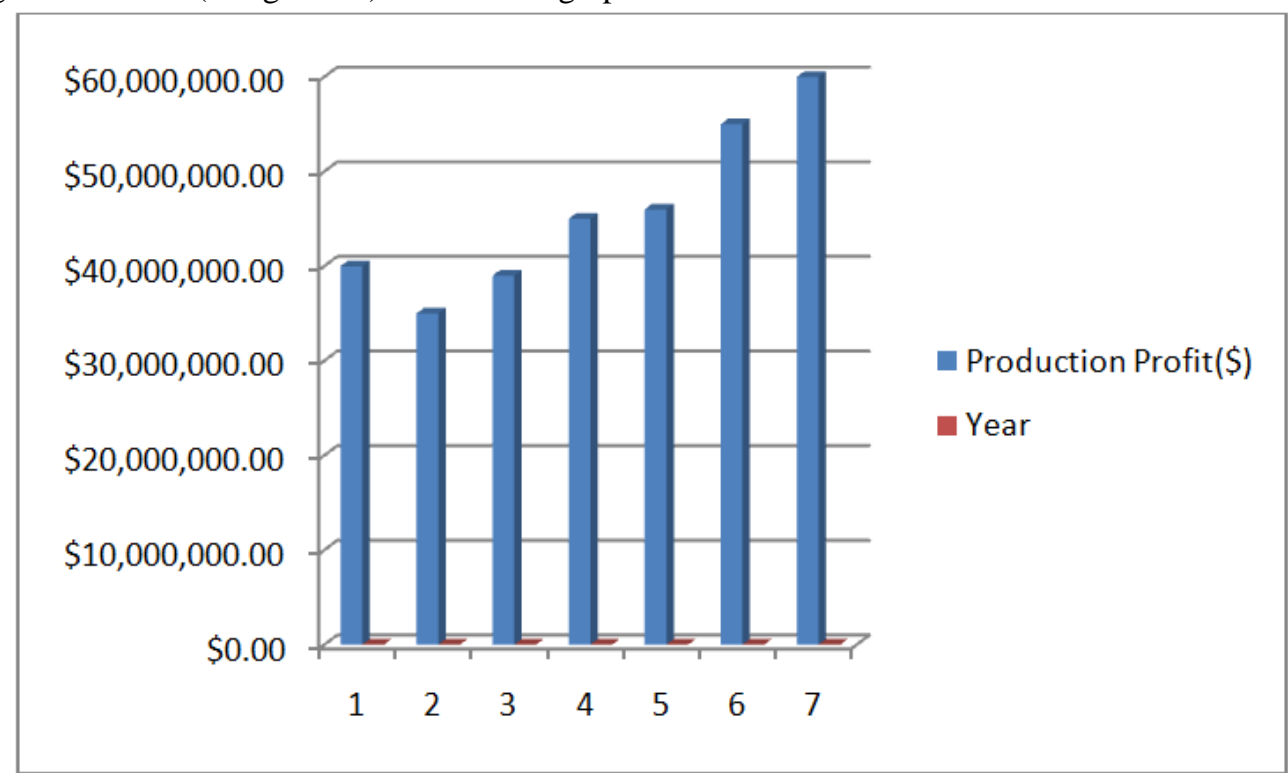

\begin{tabular}{|l|l|l|}
\hline Si No & Year & Production Profit $(\$)$ \\
\hline 1 & 2009 & $\$ 40,000,000.00$ \\
\hline 2 & 2010 & $\$ 35,000,000.00$ \\
\hline 3 & 2011 & $\$ 39,000,000.00$ \\
\hline 4 & 2012 & $\$ 45,000,000.00$ \\
\hline 5 & 2013 & $\$ 46,000,000.00$ \\
\hline 6 & 2014 & $\$ 55,000,000.00$ \\
\hline 7 & 2015 & $\$ 60,000,000.00$ \\
\hline
\end{tabular}

Here, the difference is that at starting it is up and down but at the end of the stage it is increasing. It happens cause it depends on machine maintenance, commissioning, installing etc. But if it is stared once in a time smoothy cally then there is no need to go to the backward position. As the production increasing day by day therefore it is a well wisher for Human welfare. Modern era is now more dependable because this is now efficient for mankind and it useful for social.

\section{Limitation:}

\section{Conclusion}

1. Installation process is lengthy

2. Maintenance everyday otherwise it's efficiency reduces.

3. If one part of the machines is de-active then sometimes production may be fall.

Though it has limitations but modern era is very dependable on these. Specially in pharmaceutical sector these are very effective. Without human touch of any medicine it would be acceptable to the people. Therefore, it is easily said there is no other way expect HMI and PLC based machine. 